\title{
Does percutaneous transluminal coronary angioplasty (PTCA) have comparable long-term outcomes compared to coronary artery bypass grafting $(C A B G)$ in diabetic patients?
}

\begin{abstract}
Due to the extensive nature of coronary involvement and elevated risk of restenosis, Coronary Artery Bypass Grafting (CABG) has been regarded as the mainstay of revascularization modality in diabetic patients. Nonetheless, since the introduction of drug-eluting stent, the rate of restenosis has declined significantly. Given this substantial improvement, the long-term-benefit-gap between these two revascularization strategies could have been narrowed. Our study is conducted to review and compare the long-term outcomes of PTCA with CABG in diabetic patients. The long-term treatment effects of revascularization strategies depend on the complexity and nature of the coronary vessels involved. At a low SYNTAX (Synergy between Percutaneous Coronary Intervention with Taxus and Cardiac Surgery) score, PTCA can be a reasonable alternative to CABG but an intermediate-high SYNTAX score will herald the need for CABG. In left main stem occlusion, PTCA and CABG demonstrated similar long-term outcomes. However, when the disease is accompanied by bifurcation or is classified as unprotected left main stem disease, revascularization strategy favours $\mathrm{CABG}$. Meanwhile in multivessel involvement, $\mathrm{CABG}$ confers a lower risk of all-cause mortality, myocardial infarction, repeat revascularization at the expense of increased stroke, suggesting that $\mathrm{CABG}$ is the main revascularization therapy in this patient population. Factors such as glycaemic control, feelings of being disabled and use of antiplatelet agents can potentially affect the long-term outcomes. In the future, hybrid coronary revascularization that involves both robotic surgery and PTCA might be a new trend in treating multivessel disease in diabetic patients but its clinical use needs further studies.
\end{abstract}

Keywords: coronary artery bypass grafting, percutaneous transluminal coronary angioplasty, diabetic patients, long-term outcomes, hybrid coronary revascularization, SYNTAX
Volume 7 Issue 3 - 2020

\author{
Ahmad Farouk Musa,' Cheang Jia Min,' Aizai \\ Azan Abdul Rahim, ${ }^{2}$ Jeswant Dillon, ${ }^{3}$ Rusli \\ Bin Nordin ${ }^{4}$ \\ 'Jeffrey Cheah School of Medicine \& Health Sciences, Monash \\ University Malaysia, Malaysia \\ ${ }^{2}$ Department of Cardiology, Institut Jantung Negara, Malaysia \\ ${ }^{3}$ Department of Cardiothoracic Surgery, Institut Jantung Negara, \\ Malaysia \\ ${ }^{4}$ School of Medicine, Faculty of Health \& Medical Sciences, \\ Taylor's University, Malaysia
}

Correspondence: Ahmad Farouk Musa, Jeffrey Cheah School of Medicine \& Health Sciences, Monash University Malaysia, Bandar Sunway, Malaysia, Email farouk@monash.edu

Received: July 13, 2020 | Published:September 23, 2020
Abbreviations: SYNTAX, synergy between percutaneous coronary intervention with taxus and cardiac surgery; CAD, coronary artery disease; CABG, coronary artery bypass grafting; PTCA, percutaneous transluminal coronary angioplasty; ACS, acute coronary syndrome; MODY, maturity-onset diabetes of the young; LADA, latent autoimmune diabetes of adulthood; MI, myocardial infarction; LMSD, left main stem disease; MVD, multivessel disease; DES, drug eluting stent; RCS, randomised controlled trials; OS, observational studies; BARI, bypass angioplasty revascularization investigation; MACCE, major adverse cardiac and cerebrovascular events; EES, everolimus-eluting stent; ACR, hybrid coronary revascularization

\section{Introduction}

Revascularization procedure is the cornerstone of treatment in patients with coronary artery disease (CAD). There are two methods of revascularization being widely performed worldwide, namely the Coronary Artery Bypass Grafting (CABG) and Percutaneous Transluminal Coronary Angioplasty (PTCA). Unlike CABG, PTCA is less invasive with a shorter procedural time and duration of hospital stay, and yet it is associated with a higher risk of repeat revascularization. Of patients admitted with acute coronary syndrome (ACS), it was reported that around $25-30 \%$ of patients had underlying diabetes. ${ }^{1}$ Compared to non-diabetic patients, the rate of mortality and adverse events in patients with diabetes is significantly higher. ${ }^{2-4}$ Early revascularization could enhance their prognosis. ${ }^{5}$ Nonetheless, the long-term merits of utilising either CABG or PTCA remains debatable.

\section{Aim}

Our study aims to investigate whether diabetic patients fare better in the long term with PTCA compared to CABG.

\section{Methods}

We conducted a literature search dating from January 2010 to June 2020 using PubMed, MEDLINE, Cochrane and Embase database to identify relevant articles. Medical Subject Heading (MeSH) terms such as "diabetes mellitus" "Percutaneous Transluminal Coronary Angioplasty" and "Coronary Artery Bypass Surgery" were used to identify journal articles. To allow additional relevant references selected, cross checking of references was also performed. We included studies that were (1) published from January 2010 to June 2020 with a (2) minimum duration of patient follow-up of five years regarding (3) revascularization of patients with Type 2 diabetes mellitus. 
Meanwhile, we excluded studies that were

- Published in the form of editorials, reviews and letters due to their lack of validity of prone to bias;

- regarding other subtypes of diabetes such as Type 1 diabetes mellitus, Maturity-Onset Diabetes of the Young (MODY), Latent Autoimmune Diabetes of Adulthood (LADA), impaired glucose tolerance and prediabetes states where a different mechanism of platelet dysfunction and thrombosis is involved;

- Based on revascularization for diseases such as valvular heart disease, cardiogenic shock and arrhythmias which are associated with different risks and complications; and

- Looking at repeat revascularization in patients who had previously undergone CABG and PTCA.

Data extraction was performed based on the inclusion and exclusion criteria mentioned. The primary endpoints were mortality rate, risk of myocardial infarction (MI), stroke and repeat revascularization. Table 1 for left main stem disease (LMSD), similar mortality and composite endpoints of all-cause mortality, myocardial infarction (MI) and stroke risk was found in both CABG and PTCA arms and a lower risk of target vessel revascularization was reported in the CABG arm. For multivessel disease (MVD), four observational studies and three randomised controlled trials consistently reported a significantly higher risk of repeat revascularization in patients undergoing PTCA. Conflicting data was reported regarding mortality rate, risk of myocardial infarction and stroke. In Onuma et al., ${ }^{8}$ and Kim et al., ${ }^{10}$ study, similar rate was observed (Onuma: HR:1.11, 95\% CI 0.47-2.66 $p=0.81$; Kim: HR $1.01,95 \%$ CI 0.77 to $1.33, p=0.96$ ), while in other studies, PTCA harboured a higher mortality risk. FREEDOM FollowOn study ${ }^{14}$ reports the survival rate of patients in the FREEDOM trial with an extended follow-up period. In the study, Farkouh et al. ${ }^{14}$ concluded that the mortality curves began to separate only after the second year follow-up and the discrepancy became increasingly evident when the follow-up duration was extrapolated. Meanwhile, the risk of myocardial infarction was also variable. While similar MI risk was reported in Onuma et al., ${ }^{8}$ study (HR:1.19, 95\% CI 0.38-3.76 $p=0.76$ ) and BEST Trial ${ }^{13}$ (HR: $1.76,95 \%$ CI $0.87-3.58 p=0.11$ ), a significantly higher risk was documented in the PTCA arm in Contini et al., (HR: 3.3, 95\% CI 2.4-4.6 $p<0.0001$ ) and FREEDOM study ${ }^{12}$ (PTCA: $13.9 \%$ vs CABG:6.0\%; $p<0.001$ ). Similarly, comparable risk of stroke was reported in Onuma et al., ${ }^{8}$ (HR:1.24, 95\% CI 0.42-3.65 $p=0.70$ ), Contini et al., ${ }^{9}$ study (HR: $0.8,95 \%$ CI $0.5-1.2 p=0.26$ ) and BEST Trial ${ }^{13}$ (HR: $0.86,95 \%$ CI $0.39-1.93 p=0.72$ ) but not in FREEDOM study ${ }^{12}$ (PTCA:2.4\% vs CABG: $5.2 \%$; $p=0.03$ ).

Table I Randomised controlled trials and observational studies

\begin{tabular}{|c|c|c|c|c|c|}
\hline First author & Study Design & Region & PTCA (n) & Follow-up & $\begin{array}{l}\text { All cause- mortality and adverse } \\
\text { outcomes }\end{array}$ \\
\hline Year & & & & & \\
\hline
\end{tabular}

Left Main Stem Disease (LMSD)

Yu et al., ${ }^{6} \quad$ Retrospective study China

Lee et al. ${ }^{7} \quad$ Multicenter, nonrandomised trial

Korea

PTCA: 395

12 years

CABG: 327

Total:722

PTCA: 159 years

CABG: 96

Total: 255

Multivessel disease (MVD)

Onuma et al 8 Population from ARTS I and ARTS

20 countries
All-cause mortality: Similar in both arms (HR: 0.752, 95\% Cl 0.380-I.489 $\mathrm{p}=0.4 \mathrm{I}$ )

Death, myocardial infarction and stroke: Similar in both arms

(HR:0.794, 95\% Cl: 0.463-I.36I $\mathrm{P}=0.40 \mathrm{I}$ )

Repeat revascularization: Higher in PTCA arm

(HR: 2.I I 2, 95\% Cl I.I02-4.048 $\mathrm{p}=0.024$ )

All-cause mortality: Similar in both arms (HR: I.08, 95\% Cl 0.85- I.38 p=0.54)

Death, Q-wave MI, stroke: similar in both arms

(HR: I.25, 95\% Cl 0.97-I.6I p=0.09)

Repeat revascularization: Higher in PTCA arm

(HR: 4.07, 95\% Cl 2.65-6.26 p<0.000I)

All-cause mortality: Similar in both arms (HR:I.I I, 95\% Cl 0.47-2.66 p=0.8I)

MI: Similar in both arms

(HR:I.19, 95\% Cl 0.38-3.76 p=0.76)

Stroke: Similar in both arms

(HR:I.24, 95\% Cl 0.42-3.65 $\mathrm{p}=0.70$ ) 
Table continue

\begin{tabular}{|c|c|c|c|c|c|}
\hline First author & Study Design & & PTCA (n) & Follow-up & $\begin{array}{l}\text { All cause- mortality and adverse } \\
\text { outcomes }\end{array}$ \\
\hline \multicolumn{6}{|l|}{ Year } \\
\hline & & & CABG (n) & & \\
\hline & & & & & $\begin{array}{l}\text { Repeat revascularization: Lower in } \\
\text { CABG arm } \\
\text { (HR:0.3I, 95\% Cl 0.16-0.62 p=0.00I) }\end{array}$ \\
\hline \multirow[t]{8}{*}{ Contini et al., ${ }^{9}$} & $\begin{array}{l}\text { Multicenter, non-randomised, open } \\
\text { label ARTS-Il trial }\end{array}$ & Italy & PTCA: I466 & 5 years & $\begin{array}{l}\text { All-cause mortality: Higher in PTCA } \\
\text { arm }\end{array}$ \\
\hline & & & CABG: 1419 & & (HR: I.8, 95\% Cl I.4-2.2 p<0.000I) \\
\hline & & & Total:2885 & & MI: Higher in PTCA arm \\
\hline & & & & & (HR: $3.3,95 \% \mathrm{Cl} 2.4-4.6 p<0.000 \mathrm{I})$ \\
\hline & & & & & Stroke: Similar in both arms \\
\hline & & & & & (HR: $0.8,95 \% \mathrm{Cl} 0.5-\mathrm{I} .2 \mathrm{p}=0.26)$ \\
\hline & & & & & $\begin{array}{l}\text { Repeat revascularization: Higher in } \\
\text { PTCA arm }\end{array}$ \\
\hline & & & & & (HR: 4.5, 95\% Cl 3.4-6.I p<0.000I) \\
\hline \multirow[t]{4}{*}{ Kim et al., ${ }^{10}$} & $\begin{array}{l}\text { Single-centre prospective, non- } \\
\text { randomised observational cohort } \\
\text { study }\end{array}$ & Korea & PTCA: 489 & 5.6 years & All-cause mortality: Similar in both arms \\
\hline & & & CABG: 402 & & (HR I.0I, $95 \% \mathrm{Cl} 0.77$ to I.33, $\mathrm{p}=0.96)$ \\
\hline & & & Total:891 & & $\begin{array}{l}\text { Repeat revascularization: Higher in } \\
\text { PTCA arm }\end{array}$ \\
\hline & & & & & (HR $3.69,95 \% \mathrm{Cl} 2.64$ to $5.17, \mathrm{p}<0.00 \mathrm{I})$ \\
\hline \multirow[t]{4}{*}{$\begin{array}{l}\text { Moshkovitz et } \\
\text { al.," }\end{array}$} & Retrospective study & Israel & PTCA: 27I & 62 months & $\begin{array}{l}\text { All-cause mortality: Higher in PTCA } \\
\text { arm }\end{array}$ \\
\hline & & & CABG: 226 & & $\begin{array}{l}\text { (HR:3.0I, } 95 \% \mathrm{Cl} \mathrm{I} .59 \text { to } 5.73 \\
\mathrm{p}=0.000 \mathrm{I})\end{array}$ \\
\hline & & & Total:497 & & $\begin{array}{l}\text { Repeat revascularization: Higher in } \\
\text { PTCA arm }\end{array}$ \\
\hline & & & & & (HR $7.00,95 \% \mathrm{Cl}: 3.1$ to $\mathrm{I5.70})$ \\
\hline \multirow[t]{8}{*}{$\begin{array}{l}\text { Freedom } \\
\text { Study }{ }^{12}\end{array}$} & Multicenter randomised trial & $\begin{array}{l}\text { I } 40 \text { international } \\
\text { centers }\end{array}$ & PTCA: 953 & $\begin{array}{l}2 \text { to } 6.75 \\
\text { years }\end{array}$ & $\begin{array}{l}\text { All-cause mortality: Higher in PTCA } \\
\text { arm }\end{array}$ \\
\hline & & & CABG: 947 & & (PTCA $16.3 \%$ vs CABG $10.6 \% ; p=0.049)$ \\
\hline & & & Total: 1900 & & MI: Higher in PTCA arm \\
\hline & & & & & (PTCA: $13.9 \%$ vs CABG:6.0\%; $p<0.00 I$ ) \\
\hline & & & & & Stroke: Higher in CABG arm \\
\hline & & & & & (PTCA:2.4\% vs CABG: $5.2 \% ; p=0.03$ ) \\
\hline & & & & & $\begin{array}{l}\text { Repeat revascularization: Higher in } \\
\text { PTCA arm }\end{array}$ \\
\hline & & & & & (PTCA: I $2.6 \%$ vs CABG: $4.8 \% ; \mathrm{p}<0.00 \mathrm{I}$ ) \\
\hline \multirow[t]{4}{*}{ BEST Trial ${ }^{13}$} & $\begin{array}{l}\text { Prospective, open-label, randomized } \\
\text { trial }\end{array}$ & $\begin{array}{l}\text { South Korea, } \\
\text { China, Malaysia, } \\
\text { Thailand }\end{array}$ & PTCA: 438 & I -5.2 years & All-cause mortality: Similar in both arms \\
\hline & & & CABG:442 & & (HR: I.34, 95\% Cl 0.77-2.34 p=0.30) \\
\hline & & & Total: 880 & & MI: Similar in both arms \\
\hline & & & & & (HR: I.76, 95\% Cl 0.87-3.58 p=0.II) \\
\hline
\end{tabular}


Table continue

\begin{tabular}{|c|c|c|c|c|c|}
\hline First author & Study Design & Region & PTCA (n) & Follow-up & $\begin{array}{l}\text { All cause- mortality and adverse } \\
\text { outcomes }\end{array}$ \\
\hline Year & & & & & \\
\hline
\end{tabular}

CABG (n)

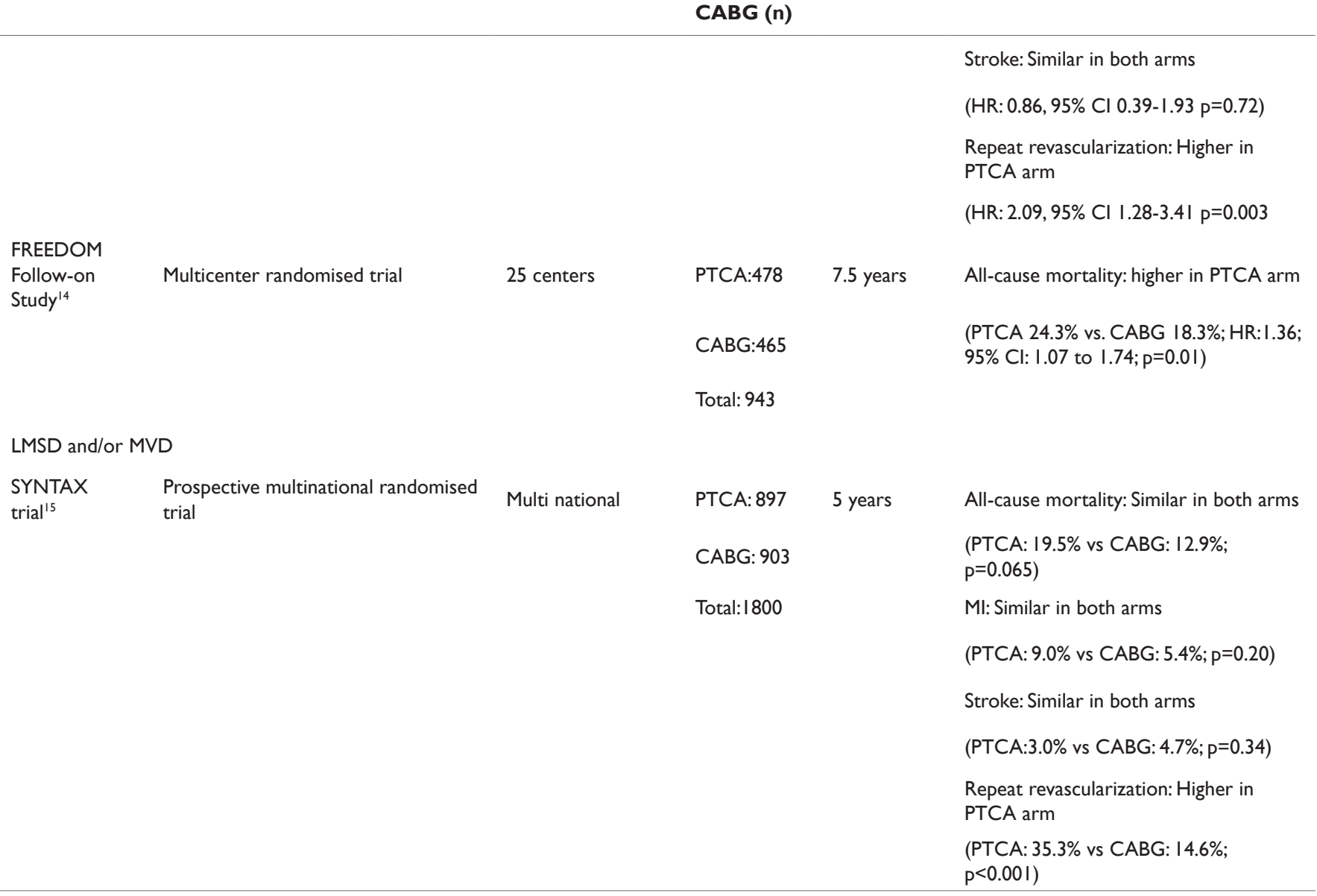

LMSD, left main stem disease; MVD, multivessel disease; MI, myocardial infarction; PTCA, percutaneous transluminal coronary angioplasty; CABG, coronary artery bypass grafting; $\mathrm{HR}$, hazard ratio; $\mathrm{Cl}$, confidence interval

SYNTAX trial ${ }^{15}$ compared treatment outcomes of PTCA and CABG in patients with LMS and/or MVD with a follow-up duration of five years. Subgroup analyses were performed to evaluate the adverse outcomes of each revascularization strategy using Synergy between Percutaneous Coronary Intervention with Taxus and Cardiac Surgery (SYNTAX) score. In SYNTAX trial, both groups demonstrated similar survival and other adverse outcomes rates but PTCA group suffered a higher burden of repeat revascularization. Referring to Figure 1, as a rule of thumb, tests for funnel plot asymmetry should only be used when there are at least ten studies included in the meta-analyses. Because when there are fewer studies, the power of the tests is too low to distinguish chance from real asymmetry. In this study, ten studies (observational and randomized trials) were included. From the Funnel Plot, it appears that there is heterogeneity (two studies as outliers) and Egger's test confirmed the plot asymmetry. (Heterogeneity: ChiSq=21.60; $\mathrm{df}=9 ; p=0.01, \mathrm{I}^{2}=58 \%$ ). This can be explained by the inclusion of both observational and randomized trials. The funnel plot could also explain the plausibility of publication bias since smaller studies with negative outcomes may not be published. Table 2 One study-level pooled analyses and four meta analyses compared the rate of mortality and adverse outcomes of PTCA-DES vs CABG in diabetic patients with a minimum of five-year follow-up. Hakeem et al. ${ }^{16}$ meta-analysis was the first systematic review and meta- analysis that compared the outcomes of PTCA-DES vs CABG for MVD in diabetic patients. Of the meta analyses identified, Huang et al., ${ }^{19}$ included the largest number of studies with a total of 19 studies comprising of four randomised controlled trials and 15 observational studies. It was the first systematic review and meta analyses that included both randomised and non-randomised studies.

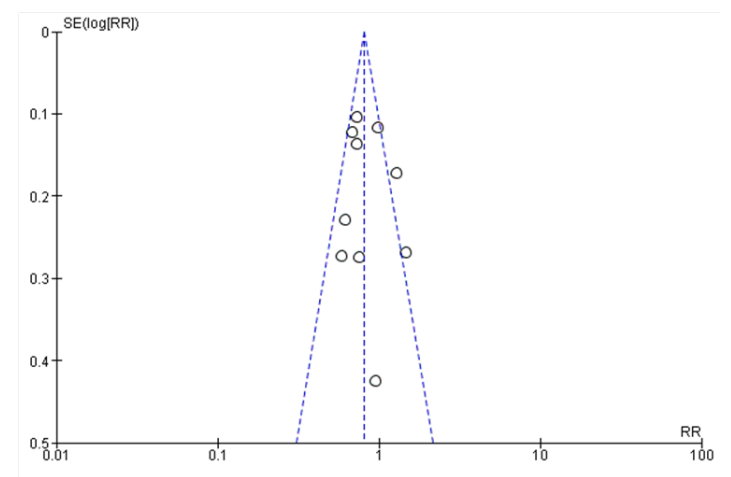

Figure I Funnel plot for assessment of publication bias of observational and randomised trials comparing CABG with PTCA for the endpoint of all-cause mortality.

$\mathrm{SE}$, standard error; RR, risk ratio 
Table 2 Meta analyses and pooled analyses

\begin{tabular}{|c|c|c|c|c|}
\hline $\begin{array}{l}\text { Author \& } \\
\text { Year }\end{array}$ & Follow up (years) & RCT & Number of patients (n) & All- cause mortality and adverse outcomes \\
\hline & & $\&$ & & \\
\hline & & $\begin{array}{l}\text { OS } \\
\text { (n) }\end{array}$ & & \\
\hline \multirow[t]{8}{*}{$\begin{array}{l}\text { Hakeem et } \\
\text { al., }{ }^{16}\end{array}$} & 2 to 5 & $\mathrm{RCT}: 4$ & PTCA: 1539 & All- cause mortality: Higher in PTCA arm \\
\hline & & OS:0 & CABG:1513 & (PTCA I4\% vs CABG9.7\%, RR I.5I, $95 \%$ CI I.09 to $2.10, p=0.01$ ) \\
\hline & & Total: 4 & Total: 3052 & Ml: Similar in both arms \\
\hline & & & & (PTCA $10.3 \%$ vs CABG $5.9 \%$, RR I. $44,95 \%$ Cl 0.79 to $2.6, p=0.23$ ) \\
\hline & & & & Stroke: Lower in PTCA arm \\
\hline & & & & (PTCA $2.3 \%$ vs CABG $3.8 \%$, RR $0.59,95 \% \mathrm{Cl} 0.39$ to $0.90, \mathrm{p}=0.0 \mathrm{I}$ ) \\
\hline & & & & Repeat revascularization: Higher in PTCA arm \\
\hline & & & & (PTCA $17.4 \%$ vs CABG $8.0 \%$, RR I.85, $95 \%$ Cl I.0 to $3.40, p=0.05$ ) \\
\hline \multirow[t]{8}{*}{$\begin{array}{l}\text { Verma et } \\
\text { al., }{ }^{17}\end{array}$} & 5 years & $\mathrm{RCT}: 8$ & Total: 3612 & All- cause mortality: Lower in CABG arm \\
\hline & & OS: 0 & & $(\operatorname{RR~} 0.67,95 \% \mathrm{Cl} 0.52-0.86 ; p=0.002)$ \\
\hline & & Total: 8 & & MI: Similar in both arms \\
\hline & & & & $(\operatorname{RR~} 0 \cdot 76,95 \%$ Cl $0 \cdot 44-1 \cdot 29 ; p=0 \cdot 30)$ \\
\hline & & & & Stroke: Higher in CABG arm \\
\hline & & & & $(\mathrm{RR} 2 \cdot 4 \mathrm{I}, 95 \% \mathrm{Cl}$ I $\cdot 22-4 \cdot 76 ; \mathrm{p}=0.0 \mathrm{I})$ \\
\hline & & & & Repeat revascularization: Lower in CABG arm \\
\hline & & & & $($ RR $0.4 I, 95 \%$ Cl $0 \cdot 29-0 \cdot 59 ; p<0 \cdot 000 I)$ \\
\hline \multirow[t]{6}{*}{ Luca et al., ${ }^{18}$} & I to 5 & RCT: 4 & PTCA: 3650 & All- cause mortality: Lower in CABG arm \\
\hline & & OS: 10 & CABG: 3422 & $\begin{array}{l}\text { (CABG } 7.3 \% \text { vs PTCA I0.4\%, } 95 \% \mathrm{Cl}: 0.65 \text { (0.55-0.77), p<0.000 I; } \\
\text { phet }=0.0000 \mathrm{I} \text { ) }\end{array}$ \\
\hline & & $\begin{array}{l}\text { Total: } \\
14\end{array}$ & Total: 7072 & Stroke: Higher in CABG arm \\
\hline & & & & $\begin{array}{l}\text { (CABG } 3.6 \% \text { vs PTCA I.4\%, 95\%Cl: } 2.34 \text { (I.63-3.35), p<0.0000I, } \\
\text { phet }=0.7 \mathrm{I} \text { ) }\end{array}$ \\
\hline & & & & Repeat revascularization: Lower in CABG arm \\
\hline & & & & $\begin{array}{l}\text { (CABG } 5.2 \% \text { vs PTCA I } 5.7 \%, 95 \% \text { Cl: } 0.30(0.25-0.36), p<0.0000 \text { I, } \\
\text { phet }=0.02 \text { ) }\end{array}$ \\
\hline \multirow[t]{8}{*}{$\begin{array}{l}\text { Huang et } \\
\text { al., }{ }^{19}\end{array}$} & I to 5.1 & $\mathrm{RCT}: 4$ & PTCA: 4502 & All-cause mortality: Similar in both arms \\
\hline & & OS: 15 & CABG:4363 & (PTCA II.7\% vs CABG 9.1\%, RR I.23, 95\% Cl I.00-1.53, $\mathrm{p}=0.06$ ). \\
\hline & & $\begin{array}{l}\text { Total: } \\
19\end{array}$ & Total: 8865 & MI: Higher in PTCA arm \\
\hline & & & & (PTCA $8.5 \%$ vs CABG $4.6 \%$, RR I.68, 95\% Cl I.20-2.37, p=0.003) \\
\hline & & & & Stroke: Lower in PTCA arm \\
\hline & & & & (PTCA $2.0 \%$ vs CABG $3.9 \%$, RR $0.51,95 \%$ Cl $0.39-0.67, p<0.0000 I$ ) \\
\hline & & & & Repeat revascularization: Higher in PTCA arm \\
\hline & & & & (PTCA 19.0\% vs CABG 6.3\%, RR 2.95, 95\% Cl 2.46-3.55, $p<0.00001$ ) \\
\hline
\end{tabular}

MVD, multivessel disease; LMSD, left main stem disease; F/U, follow-up; RCT, randomised controlled Trials; OS, observational studies; MI, myocardial infarction; PTCA, percutaneous transluminal coronary angioplasty; CABG, coronary artery bypass grafting; $\mathrm{HR}$, hazard ratio; $\mathrm{Cl}$, confidence interval; RR, relative risk; OR, odds ratio 
Meanwhile, Cui et al., ${ }^{20}$ study, being the latest meta-analyses published, had the longest period of follow-up and the highest number of diabetic patients $(\mathrm{n}=17532)$. In the meta-analysis, three studies that compared the newer second-generation drug eluting stent (DES), namely, Everolimus with CABG were enrolled. Unlike the results from randomised controlled trials and observational trials, results from meta analyses are largely consistent that CABG confers a lower risk of all-cause mortality, myocardial infarction and repeat revascularization at the cost of increased stroke. Two exceptions to the results are found in Hakeem et al., ${ }^{16}$ and Verma et al., ${ }^{17}$ studies. In Hakeem et al., ${ }^{16}$ study, the risk of myocardial infarction was similar in CABG and PTCA arms (10.3\% versus 5.9\%, RR 1.44, 95\% CI 0.79 to 2.6, $p=0.23$ ) but PTCA group showed a trend towards higher risk of myocardial infarction. According to Hakeem et al., ${ }^{16}$ this phenomenon was attributable to the presence of VA CARDs trial which led to significant heterogeneity in the studies. Of note, after excluding VA CARDs trial, MI risk reached statistical significance (RR 2.01, 95\% CI 1.54 to $2.62, p<0.0001)$ without residual heterogeneity ( $\mathrm{I}^{2}=0 \%$, $p=0.83$ ). Similarly, in Verma et al., ${ }^{17}$ study the increase in risk of MI became significant (RR $0.57,95 \%$ CI $0.41-0.78 ; p=0.0004$ ) after VA CARDs study was excluded from analysis $\left(\mathrm{I}^{2}=0 \%\right)$. On the other hand, Huang et al., ${ }^{19}$ performed a sensitivity analyses separately with VA CARDS trial excluded and reported that the overall MI rate did not alter regardless of the presence of VA CARDS trial (inclusion: 8.5\% DES vs. $4.6 \%$ CABG, RR $1.68,95 \%$ CI $1.20-2.37, p=0.003$; exclusion: $8.6 \%$ DES vs. $4.3 \%$ CABG, RR $1.91,95 \%$ CI $1.43-2.57$, $p<0.0001)$. Nonetheless, it is worth noting that Huang et al., ${ }^{19}$ analysed 14 randomised and non-randomised studies as opposed to Hakeem et al. ${ }^{16}$ and Verma et al., ${ }^{17}$ who only analysed four and eight randomised studies in their meta-analyses, respectively.

\section{Discussion}

Over the past decade, the prevalence of diabetes is on the rise, with more than a two-fold rise seen in both genders. ${ }^{2}$ Of patients presenting with ACS, around $25-30 \%$ of patients suffered from diabetes. ${ }^{1}$ Unfortunately, it was found that post-myocardial infarction complications and deaths are higher in diabetic patients after CABG or PTCA compared with non-diabetic patients. ${ }^{3-5}$ A report analysis of EXCEL trial ${ }^{21}$ documented that diabetic patients sustained a higher composite end point of death, stroke and MI after CABG (HR: 1.55; 95\% CI: 1.04 to $2.31 ; p=0.03$ ) or PTCA (HR: $1.53 ; 95 \%$ CI: 1.04 to 2.26; $p=0.03$ ) than non-diabetic population. Furthermore, in contrast to healthy individuals, diabetic patients suffered a higher rate of wound infection, neurological and renal complications, higher risk of stroke and readmission following CABG and increased rates of target lesion revascularization and reinfarction after PTCA. ${ }^{5}$ Worse, diabetic patients also tend to present with a number of comorbidities at diagnosis, which further worsened their prognosis. ${ }^{22,23}$ Despite this, indications for revascularization therapy did not differ for diabetic and non-diabetic patients. ${ }^{1}$ Nonetheless, in a nationwide study, ${ }^{4}$ it was reported that, compared to patients without diabetes, diabetic patients are less likely to undergo myocardial revascularization procedures for fear of post-procedural complications and death. The higher frequency of proximal stenosis and extensive involvement in diabetic patients also confers a higher procedural risk, hence decreasing the favourability for revascularization as a treatment option for ACS. ${ }^{4,24}$

However, it has been shown that early revascularization offers higher benefits in diabetic patients by reducing the risk of adverse events. ${ }^{4,25}$ A meta-analysis ${ }^{26}$ with inclusion of eight trials found that early invasive strategy could reduce the mortality by $36 \%$ (HR: 0.67 , 95\% CI: 0.45-0.99). In the past, CABG seemed to be the default treatment strategy for patients with diabetes due to their nature of multivessel involvement and a higher risk of restenosis. ${ }^{5}$ Since the introduction of PTCA by Dr Andreas Gruntzig in 1977, PTCA enjoyed numerous notable advances over the few decades which has greatly improved its success rate with a better safety profile. ${ }^{27}$ This improvement becomes more evident after the introduction of drug-eluting stent (DES) which has drastically decreased the rate of restenosis of PTCA. ${ }^{27-30}$ Given the advances, whether PTCA could replace $\mathrm{CABG}$ as an ideal treatment modality, remains unknown. Long term follow-up of patients is essential because the adverse outcomes of some treatments might not be obvious on a short-term follow up and the effects might also alter in the long run. For example, a study conducted by Pederson et al., ${ }^{31}$ which compared the cause of short-term and long-term mortality in patients treated with primary PTCA for ST segment elevation myocardial infarction showed that cardiac mortality remained the main cause of death within the first month of PTCA. Beyond the first month, the origin of death began to shift towards non-cardiac causes. In addition, Onuma et al., ${ }^{8}$ also documented that late stent and very late stent thrombosis constitutes around two-thirds of stent thrombosis. To our knowledge, to date, the longest-term follow-up with regards to the outcomes of CABG and PTCA is 40 years. ${ }^{32}$ Nonetheless currently, there are only limited studies that follow up patients for such a long duration. According to Hakeem et al., ${ }^{16}$ the merits of CABG significantly outweigh PTCA after four years of revascularization (pooled Absolute risk reduction $=6 \%$ ), hence the cut-off point of a five-year follow-up duration was adopted in our study.

Randomised controlled trials (RCTs) are gold standard in comparing the clinical outcomes of treatments of a disorder and yet, the recruited patients in the RCTs are usually specifically selected and patients who have multiple comorbidities are excluded, thus preventing true reflection of the real-world clinical practice. In contrast, despite a significant level of selection, publication and treatment bias, observational studies (OS) could reflect daily clinical practice in the hospital setting. According to Huang et al., ${ }^{19}$ patients from observational studies enjoyed a considerably higher mortality benefit with $\mathrm{CABG}$ than patients from randomised trials (Observational trials $9.6 \%$ vs. Randomised trials $11.9 \%$, RR 0.81 , $95 \%$ CI $0.71-0.92, p=0.001)$. This suggests that in the real setting, CABG is a desired choice of revascularization for patients with high risk profiles. Hence, it is essential to take into account the findings of both RCT and OS as demonstrated in our study so that the overall treatment effect of CABG and PTCA can be determined clinically and statistically.

Studies: With respect to LMSD and/or MVD in diabetic patients, there are some remarkable studies that merit discussion. Bypass Angioplasty Revascularization Investigation (BARI) ${ }^{33}$ is the first study that outlined the survival advantage of CABG over PTCA in diabetic patients. After an analysis of 353 diabetic patients at 5 -year follow up, a two-fold risk of mortality rate related to PTCA was found. As a consequence, a recommendation of CABG as an optimal revascularization method in patients with diabetes was made. Unfortunately, albeit being historically crucial, as the study was conducted before the introduction of DES and antiplatelet agents, the study has limited application to the current clinical setting. ${ }^{5,12,34}$ Following BARI study, several other studies on diabetes and MVD disease emerged including EAST trial, CARBI trial, RITA trial, ARTS trial, SYNTAX trial and CARDia Trial..$^{5,12}$ Notably, as EAST trial, CARBI trial and RITA trial were too flawed to allow meaningful conclusions to be derived, they are not discussed here. ARTS trial ${ }^{35}$ was the first randomised trial performed that compared the five-year 
outcomes of patients with MVD treated with CABG versus BMS Meanwhile, CARDia trial ${ }^{34}$ was the first prospective randomised trial that evaluated coronary revascularization in diabetic patients while SYNTAX trial ${ }^{15}$ utilised SYNTAX score to measure the extent of coronary vessels occlusion. Interestingly, ARTS trial, SYNTAX trial and CARDia trial consistently reported similar mortality rate with excess major adverse cardiac and cerebrovascular events (MACCE) rate in the PTCA group, driven by an increased need for repeat revascularization. ${ }^{6}$ Regrettably, these three studies encountered critics from multiple recent studies ${ }^{6,17}$ such as use of historical control in ARTS trial, CARDia study being underpowered for primary composite outcome and utilisation of subgroup analysis of diabetic patients in SYNTAX trial. This led to the validity of their results being questioned.

FREEDOM study ${ }^{12}$ is the greatest prospective randomised trial which assigned a total of 1900 diabetic patients with MVD from 2005 to 2010 at 140 international centres to either CABG or PTCA followed by a follow-up period of between 2 to 6.75 years to evaluate the adverse outcomes. Given its recruitment of diabetic patients in particular, inclusion of high risk patients with a good distribution of SYNTAX scores as well as utilisation of optimal medical therapy throughout follow-up, the study was regarded as the most outstanding trial to detect the safety and efficacy of revascularization therapies for diabetic patients with MVD and was therefore included in most of the meta-analyses available. Worth noting, FREEDOM study is the only study that was included in all the meta-analyses highlighted in our report. To further evaluate the survival advantage of CABG over PTCA, FREEDOM Follow-On study ${ }^{14}$ was published on 2019 with an extended median follow-up of 7.5 years. The other study that was evaluated in numerous meta-analyses is VA CARDS study. Aside from Luca et al. ${ }^{18}$ study VACARDS study was analysed by all the meta analyses mentioned above. With the belief that silent MIs are responsible for around one-third of the total MI in diabetic patients, VA CARDS study ${ }^{16,17,36}$ aggressively searched for silent MIs. As such, the risk of non-fatal MI was elevated drastically following CABG (CABG: $15 \%$ PCI:6.2\% , HR: 3.32; 95\% CI: 1.07 to 10.30). However, this study was not discussed in our study as the follow-up duration failed to meet our inclusion criteria. BEST trial ${ }^{13}$ was one of the few randomised trials that compared Everolimus-eluting stent (EES) with CABG in patients with diabetes and MVD. With respect to safety and efficacy, EES was demonstrated to be the most efficacious stent as it was associated with the lowest risk of stent thrombosis and repeat revascularization. ${ }^{28,30,37}$

Bangalore et al., ${ }^{38}$ evaluated the treatment outcomes of CABG and EES for diabetic patients with MVD and reported that EES provided a similar survival benefit as CABG $(425[10.50 \%]$ versus $414[10.23 \%]$ events; HR $=1.12 ; 95 \%$ CI, $0.96-1.30 ; p=0.16$ ) and a lower risk of stroke $(118$ [2.92\%] versus 157 [3.88\%] events; HR=0.76; 95\% CI, $0.58-0.99 ; p=0.04)$ at the expense of a higher risk of myocardial infarction $(260[6.42 \%]$ versus $166[4.10 \%]$ events; HR=1.64; 95\% CI, 1.32-2.04; $p<0.0001)$ and repeat revascularization (889 [21.96\%] versus $421[10.40 \%]$ events; $\mathrm{HR}=2.42 ; 95 \% \mathrm{CI}, 2.12-2.76 ; p<0.0001)$ driven by incomplete revascularization at long term. Nevertheless, in BEST trial, it was shown that CABG still outperformed PTCA even with EES. As the current evidence is inconsistent, future welldesigned studies are required to allow a meaningful conclusion to be drawn. In LMSD, comparable adverse outcomes and mortality was observed in CABG and PTCA. ${ }^{7,39}$ It could be argued that the above studies were underpowered as they did not utilise newer secondgeneration drug-eluting stent, Everolimus. NOBEL trial ${ }^{40}$ and EXCEL trial ${ }^{41}$ were two largest randomised trials that included Everolimus but they were not powered to study diabetic patients exclusively. In a subgroup analysis of EXCEL trial, ${ }^{21}$ it was reported that the composite risk of all-cause mortality, stroke and myocardial infarction did not differ between CABG and PTCA in diabetic patients at 3 years (PTCA $20.7 \%$ vs. CABG $19.3 \%$; HR: 1.03 ; $95 \%$ CI: 0.71 to $1.50 ; p=0.87$ ) but there was a high risk of repeat revascularization in the PTCA arm ( $p=0.01$ ). These results were consistent with the findings in our study. One exception is that all-cause mortality was found to be higher in the PTCA arm $(p=0.046)$ due to inclusion of diabetic patients with high SYNTAX scores.

Noteworthy, the use of PTCA as a substitute for CABG can only be indicated to selected LMSD patients. It was found that CABG yield better outcomes in patients with bifurcation lesions and unprotected LMSD. Kappetein and $\mathrm{Head}^{42}$ reported that LMSD associated with bifurcation incurred a higher risk of procedural complications, repeat revascularization and thrombosis, thus favouring $\mathrm{CABG}$ as the treatment option. Although similar adverse effects and mortality were found in both PTCA and CABG arms in Yu et al., ${ }^{6}$ study where effects of unprotected LMSD were looked at, as an unprotected left main stem occlusion is highly associated with MVD, CABG could be a more reasonable revascularization modality in this patient population. ${ }^{42}$ For MVD, as opposed to the pooled analyses or meta-analyses, in terms of adverse outcomes and mortality, a large variation has been observed in the individual studies. This phenomenon is contributed by various study design, types of stents or grafting and inclusion and exclusion criteria. Hence, the results from individual studies should be interpreted with caution. To summarise, the long-term survival in MVD favours CABG. Herbison and Wong ${ }^{43}$ performed a comprehensive meta-analysis of 14 randomised trials and concluded that despite significant improvement of CABG and PTCA over the past 30 years, particularly in diabetic patients, CABG still constantly outperformed PTCA by $30 \%$ difference in survival benefit regardless of the types of stents used. Similarly, another pooled analysis ${ }^{44}$ of 10 randomised trials involving CABG and PTCA for diabetic patients with MVD also demonstrated a significantly lower five-year mortality rate in the CABG arm (12.3\% versus $20.0 \%$; HR $0.70 ; 95 \%$ CI 0.56 to $0.87, p=0.014)$. For the long-term adverse outcomes, from the studies above, it can be concluded that the overall effects of CABG are more feasible than PTCA. Some explanations to its treatment effect include its ability to achieve complete revascularization and its lower rate of restenosis. ${ }^{45}$ In Contini et al., ${ }^{9}$ study there were $85.6 \%$ of CABG patients undergoing complete revascularization but only $51.3 \%$ of PTCA patients managed to do so. Meanwhile, Farooq et al., ${ }^{46}$ reported that in his study, compared with $66.9 \%$ of CABG patients, angiographic complete revascularization was only achieved in $52.8 \%$ of PTCA patients. Worse, the burden of incomplete revascularization will be further complicated by the presence of diabetes. According to Verma et al. ${ }^{17}$ and Aronson et al. ${ }^{45}$ diabetic population tend to present with more progressive and diffuse coronary disease and new lesions can also form easily in the revascularization sites along with the progression of diabetes.

For restenosis rate, target vessel revascularization remained as an unwanted effect related to PTCA. Multivessel angioplasty risks a higher chance of restenosis at multiple independent sites and will potentially worsen the overall treatment outcomes. ${ }^{5}$ Worse, the occurrence of stent thrombosis is elevated significantly with the presence of diabetes and coronary artery disease, thus markedly decreasing the benefit of PTCA in diabetic patients. ${ }^{11,21}$ In spite of being more invasive, ${ }^{18}$ Aronson et al. ${ }^{45}$ noted that $\mathrm{CABG}$ possesses a greater freedom from reintervention for concomitant diabetic and MVD patients. Unfortunately, CABG harboured a higher risk of stroke 
which can be explained by infrequent use of antiplatelet agents after $\mathrm{CABG}$ and the use of on-pump CABG. ${ }^{20}$ Noteworthy, in FREEDOM, 30 days after revascularization, the use of aspirin in PTCA versus CABG was $99.1 \%$ versus $88.4 \%$ while the use of thienopyridine was only $98.4 \%$ and $24.6 \%$ for PTCA and CABG, respectively. 12,17 Diabetic patients were found to have abnormal platelets and an enhanced platelet activity, which leads to enhanced adhesion, activation and aggregation..$^{47,48}$ In view of this association, antiplatelet agents could play a vital role in reducing the risk of thrombosis in diabetic population. This theory was supported by a previous study which suggested that twice-daily aspirin regimen in place of once daily regimen for diabetes population afflicted with coronary artery disease could be more efficacious in hindering platelet production and platelet aggregation in patients with diabetes. ${ }^{49}$ Hence, undoubtedly, given the lower frequency of antiplatelet use post $\mathrm{CABG}$, the risk of stroke is higher. Another aspect regarding the enhanced stroke risk is the utilisation of aortic manipulation in on-pump CABG. It was postulated that aortic manipulation can cause atherosclerotic debris to occlude the blood vessels in the brain, leading to stroke. Also, prophylactic anti-platelet therapy, weeks before CABG with aortic manipulation and on-pump $\mathrm{CABG}$, might reduce the risk of stroke. Nonetheless, whether the use of off-pump CABG could decrease the incidence of stroke remains debatable. A retrospective analysis ${ }^{50}$ of 30,426 patients undergoing CABG surgery in 2006 and 2007 reported a lower occurrence of stroke with off-pump CABG than on-pump CABG (adjusted odds ratio: $0.76,95 \% \mathrm{CI} 0.59$ to $0.98, p<0.001$ ). This contrasts with a recent meta-analysis which analysed 8145 patients in six studies and reported comparable incidence of stroke with on-pump and off-pump CABG at 5-year follow-up (OR: 0.78; 95\% CI: 0.56 to $1.10 ; p=0.16 ; 2.2 \%$ vs. $2.8 \%) .{ }^{51}$ Yamagata et al. ${ }^{52}$ evaluated the adverse outcomes of sirolimus eluting stent versus off-pump CABG in a nonrandomised trial of 207 diabetic patients with MVD and revealed a significantly higher rate of cerebrovascular events following off-pump CABG $(p=0.035)$ at 3 years. Based on this finding, it can be inferred that although the risk of stroke may decline with off-pump CABG, the outcomes did not appear to alter considerably when compared with PTCA, if other factors remain unchanged. Future well-designed studies are warranted to validate this hypothesis.

Effect of SYNTAX score: SYNTAX score was developed to grade the complexity of coronary vessels in patients with CAD in order to determine the feasibility of CABG or PTCA..$^{53}$ It was suggested that the presence of diabetes can increase the complexity of coronary lesions. ${ }^{54}$ In SYNTAX trial, ${ }^{15}$ revascularization benefits did not differ in patients with low-intermediate SYNTAX score. For patients with intermediate-high SYNTAX score, increasing adverse events were reported in PTCA cohort with increasing SYNTAX score. Interestingly, such effect was more apparent in diabetic patients than non-diabetic individuals. Therefore, it can be concluded that, in diabetic patients, when the SYNTAX score is low, PTCA can be recommended but when the SYNTAX score is high, CABG should be the default revascularization modality. ${ }^{1,55}$ This applies to both LMSD occlusion and MVD. In a subgroup analysis of EXCEL Trial ${ }^{21}$ involving 554 diabetes patients, at high SYNTAX scores, there was a significant mortality difference between CABG and PTCA. Although EXCEL trial was underpowered in assessing mortality in diabetic patients, the trend towards improved survival was evident. In light of this effect, it was recommended that the use of SYNTAX score is paramount in clinical decision making for patients with LMSD and MVD. ${ }^{1}$ On a side note, VA CARDs trial ${ }^{3}$ did not identify the effect of SYNTAX score on the revascularization outcomes. However, it is crucial to note that the study was underpowered with merely a limited number of participants and follow-up duration.
Confounding factors: Several factors should be considered when determining the long-term adverse outcomes of CABG and PTCA. Glycaemic control plays a pivotal role in altering the treatment outcomes of revascularization therapy. Of all parameters, the value of $\mathrm{HbA} 1 \mathrm{c}$ is of the utmost importance. ${ }^{56,57}$ It was interesting that the level of $\mathrm{HbAlc}$ has been found to be associated with spontaneous platelet aggregation and might reflect underlying hypercoagulable status in diabetes. ${ }^{58}$ Harskamp and Park ${ }^{59}$ noted that in a study conducted by Corpus et al., ${ }^{60}$ when the HbAlc was above 7, the rate of target vessel revascularization after PTCA was enhanced significantly $(34 \%$ vs. $15 \%, p=0.02$ ). Moreover, a meta-analysis ${ }^{61}$ of 16 studies also suggested that high $\mathrm{HbAlc}$ at baseline can independently increase the risk of major adverse cardiovascular and cerebrovascular events (MACCE) in diabetic patients receiving PTCA with a risk ratio of $1.18\left(95 \%\right.$ CI $\left.1.10-1.27, p=0.016 ; \mathrm{I}^{2}=45.8 \%\right)$. Likewise, in an observational study, ${ }^{53}$ the incidence of MACCE was significantly lower when $\mathrm{HbAlc}$ is below 7 (27.5\% versus $37.4 \%$; $\mathrm{HR}, 0.71$; $95 \%$ CI, $0.52-0.97 ; p=0.03$ ) which is driven by significant reduction of repeat revascularization $(19.9 \%$ versus $29.5 \%$; HR, $0.66 ; 95 \% \mathrm{CI}$, $0.47-0.93 ; p=0.02$ ) and this benefit was maximised when the residual SYNTAX score was above four. Interestingly, psychological factors were also found to be potential determinants of mortality of PTCA. In a recent study, ${ }^{62}$ at 12-year follow-up, patients with higher feelings of being disabled one month after PTCA had a significantly higher mortality rate $(43.5 \%$ vs $23.1 \%$; $\mathrm{HR}=2.53,95 \% \mathrm{CI}=1.30-4.90$, $p=0.001)$. As currently there is insufficient data looking at this aspect, future robust studies are required to determine their relationship. The presence of diabetes can lead to a thrombotic state via various mechanism. ${ }^{63}$ Antiplatelet agents play a crucial role in minimising the risks of hypercoagulability. Over several decades, aspirin and clopidogrel were regarded as the cornerstone of antiplatelet regimens. However, it has been proposed that newer antiplatelet agents, namely Ticagrelor and Prasugrel, generate more favourable outcomes than the older medications, particularly in diabetic patients. ${ }^{64,65}$ In a meta-analysis ${ }^{66}$ of seven randomised controlled trials involving 58,591 patients with ACS, patients with Ticagrelor or Prasugrel had a significant decline in mortality $(2.9 \%$ vs. $3.4 \%, \mathrm{OR}=0.87,95 \%$ CI $0.79-0.95, p=0.002)$, recurrent myocardial infarction $(4.2 \%$ vs. $5.2 \%$, OR $=0.80,95 \%$ CI $0.74-0.87, p<0.0001)$ and definite instent thrombosis $(0.9 \%$ vs. $1.7 \%$, OR $=0.52,95 \%$ CI $0.43-0.63$, $p<0.0001)$ without an elevation of major bleeding complications $(5 \%$ vs. $4.7 \%, \mathrm{OR}=1.0695 \%$ CI $0.96-1.17, p=0.25$ ). These results were in agreement with the OPTIMUS trial ${ }^{59}$ that demonstrated a greater inhibition of platelet activity by Prasugrel than Clopidogrel (89.3 vs. $27.7 \%, p=0.0001$ ). To date, as the evidence with regards to the clinical efficacy and safety of Ticagrelor and Prasugrel post revascularization therapy is lacking, well-designed studies looking at this aspect are warranted.

\section{Limitations}

First of all, despite our best effort to include similar studies and exclude studies which present significant heterogeneity from the other studies, given various inclusion and exclusion criteria and study designs, a number of variables still exist between the studies. Definition of the adverse outcomes, follow-up duration and types of grafting which differ from one study to another can potentially affect the treatment outcomes. In addition, factors such as HbAlc level, SYNTAX score, treatment of diabetes and psychological factors were not captured in the aforementioned studies. Besides, since we only included studies that are published in English, a limited number of studies were analysed. Moreover, given the restricted number of studies which utilised EES, the results should be interpreted 
cautiously when applied to the clinical setting where EES is widely performed. Future robust studies utilising EES are warranted. Lastly, several observational studies were recruited in our study where they posed inherent bias. Despite so, it seemed unlikely that the results would differ considerably after exclusion of the observational trials.

\section{Future directions}

The more extensive and severe atherosclerotic plaque in the coronary vessels of diabetic patients leads to the emergence of hybrid coronary revascularization (HCR) ${ }^{67} \mathrm{HCR}$, as its name suggests, combines the essence of CABG and PTCA to mitigate the issues related to MVD. ${ }^{68}$ In HCR, CABG is performed in the left anterior descending artery while PTCA is utilised to open up the other occluded vessels. ${ }^{69,70}$ This minimally invasive CABG procedure was done using a robotic procedure where only small incisions were required rather than a midline incision. This is considered as the best of both worlds strategy where a minimally-invasive off-pump left internal mammary graft was connected to the blocked left anterior descending artery, and a stent was then placed from the left main to the left circumflex artery. As compared to CABG and PTCA, HCR is safer and more effective. Owing to the fact that HCR avoids sternotomy, cardiopulmonary bypass and most importantly, aortic manipulation, it is associated with a lower infection, transfusion and prolonged recovery rate and risk of stroke..$^{62,64,71,72}$ As mentioned previously, diabetic patients are associated with more frequent infections with a slower healing rate. Therefore, HCR could provide enormous benefits to this population. In a randomised study ${ }^{62}$ of 191 patients with MVD, at five years, HCR had a similar all-cause mortality $(6.4 \%$ for HCR vs. $9.2 \%$ for CABG; $p=0.69)$, myocardial infarction $(4.3 \%$ vs. $7.2 \% ; p=0.30)$, repeat revascularization $(37.2 \%$ vs. $45.4 \% ; p=0.38)$, stroke $(2.1 \%$ vs. $4.1 \% ; p=0.35)$ and MACCE s (45.2\% vs. $53.4 \% ; p=0.39)$ but a trend towards better outcomes favouring HCR as compared to patients with conventional CABG. A prospective study ${ }^{61}$ was performed in Fuwai Hospital which enrolled 120 diabetic patients in the HCR arm and 240 patients in the off-pump CABG arm with a follow-up of MACCE events after three years. At three years, the rate of stroke in the CABG arm were reported to be lower ( $0 \%$ vs $3.6 \%$ at 3 years; $p=0.046)$. The expansion of the utilisation of HCR is anticipated in the years to come. ${ }^{73}$ Currently, there is insufficient evidence to guide the application of the procedures to diabetic patients. ${ }^{66,67,74}$ Hence, future robust studies on long-term follow up could offer a better guidance.

\section{Conclusions}

The option of revascularization in diabetic patients is largely based on the complexity and nature of coronary vessels involved. When the SYNTAX score is low, PTCA can be performed as an alternative to CABG. At intermediate-high SYNTAX score, CABG is preferred. Meanwhile, CABG remains the mainstay of treatment in multivessel involvement or complex CAD. In left main stem occlusion, when the disease is accompanied by bifurcation or is classified as unprotected left main stem disease, CABG could offer better treatment outcomes. Other factors such as patient's quality of life, cost effectiveness of therapy, other clinical factors and short-term clinical outcomes should also be taken into account in clinical decision making and should be communicated effectively with the patients. It is imperative to implement shared decision making when formulating the best revascularization option so that patients' preferences, values and needs can be respected and honoured.

\section{Acknowledgments}

None.

\section{Conflicts of interest}

The authors declare that they have no conflicts of interests.

\section{Funding}

None.

\section{References}

1. Neumann FJ, Sousa-Uva M, Ahlsson A, et al. 2018 ESC/EACTS guidelines on myocardial revascularization. Eur Heart J. 2019;40(2):87165 .

2. Zhou B, Lu Y, Hajifathalian $\mathrm{K}$, et al. Worldwide trends in diabetes since 1980: a pooled analysis of 751 population-based studies with 4.4 million participants. Lancet. 2016;387(10027):1513-1530

3. King SB, Marshall JJ, Tummala PE. Revascularization for coronary artery disease: stents versus bypass surgery. Аппи Rev Med. 2010;61:199-213.

4. Gustafsson I, Hvelplund A, Hansen KW, et al. Underuse of an invasive strategy for patients with diabetes with acute coronary syndrome: a nationwide study. Open Heart. 2015;2(1):e000165.

5. Singh M, Arora R, Kodumuri V, et al. Coronary revascularization in diabetic patients: current state of evidence. Exp Clin Cardiol. 2011;16(1):16-22.

6. Yu X, He J, Luo Y, et al. Influence of diabetes mellitus on long-term outcomes of patients with unprotected left main coronary artery disease treated with either drug-eluting stents or coronary artery bypass grafting. Int Heart J. 2015;56(1):43-48

7. Lee K, Ahn JM, Yoon YH, et al. Long-term (10-year) outcomes of stenting or bypass surgery for left main coronary artery disease in patients with and without diabetes mellitus. J Am Heart Assoc. 2020;9(8):e015372.

8. Onuma Y, Wykrzykowska JJ, Garg S, et al. 5-Year follow-up of coronary revascularization in diabetic patients with multivessel coronary artery disease. JACC Cardiovasc Interv. 2011;4(3):317-323.

9. Contini GA, Nicolini F, Fortuna D, et al. Five-year outcomes of surgical or percutaneous myocardial revascularization in diabetic patients. Int $J$ Cardiol. 2013;168(2):1028-1033.

10. Kim YG, Park DW, Lee WS, et al. Influence of diabetes mellitus on long-term (five-year) outcomes of drug-eluting stents and coronary artery bypass grafting for multivessel coronary revascularization. $\mathrm{Am} \mathrm{J}$ Cardiol. 2012;109(11):1548-1557.

11. Moshkovitz Y, Mohr R, Medalion B, et al. Drug-eluting stents compared with bilateral internal thoracic artery grafts for diabetic patients. Ann Thorac Surg. 2012;94(5):1455-1462.

12. Farkouh ME, Domanski M, Sleeper LA, et al. Strategies for multivessel revascularization in patients with diabetes. $N$ Engl $J$ Med. 2012;367(25):2375-2384.

13. Park SJ, Ahn JM, Kim YH, et al. Trial of everolimus-eluting stents or bypass surgery for coronary disease. $N$ Engl J Med. 2015;372(13):12041212.

14. Farkouh ME, Domanski M, Dangas GD, et al. Long-term survival following multivessel revascularization in patients with diabetes: the freedom follow-on study. J Am Coll Cardiol. 2019;73(6):629-638.

15. Kappetein AP, Head SJ, Morice MC, et al. Treatment of complex coronary artery disease in patients with diabetes: 5-year results comparing outcomes of bypass surgery and percutaneous coronary intervention in the SYNTAX trial. Eur J Cardiothorac Surg. 2013;43(5):1006-1013.

16. Hakeem A, Garg N, Bhatti S, et al. Effectiveness of percutaneous coronary intervention with drug-eluting stents compared with bypass surgery in diabetics with multivessel coronary disease: comprehensive systematic review and meta-analysis of randomized clinical data. $J \mathrm{Am}$ Heart Assoc. 2013;2(4):e000354. 
17. Verma S, Farkouh ME, Yanagawa B, et al. Comparison of coronary artery bypass surgery and percutaneous coronary intervention in patients with diabetes: a meta-analysis of randomised controlled trials. Lancet Diabetes Endocrinol. 2013;1(4):317-328.

18. De Luca G, Schaffer A, Verdoia M, et al. Meta-analysis of 14 trials comparing bypass grafting vs drug-eluting stents in diabetic patients with multivessel coronary artery disease. Nutr Metab Cardiovasc Dis. 2014;24(4):344-354.

19. Huang F, Lai W, Chan C, et al. Comparison of bypass surgery and drugeluting stenting in diabetic patients with left main and/or multivessel disease: a systematic review and meta-analysis of randomized and nonrandomized studies. Cardiol J. 2015;22(2):123-134.

20. Cui K, Lyu S, Song X, et al. Drug-eluting stent versus coronary artery bypass grafting for diabetic patients with multivessel and/or left main coronary artery disease: a meta-analysis. Angiolgy. 2019;70(8):765-773.

21. Milojevic M, Serruys PW, Sabik JF, et al. Bypass surgery or stenting for left main coronary artery disease in patients with diabetes. $\mathrm{J}$ Am Coll Cardiol. 2019;73(13):1616-1628.

22. Foussas SG. Acute coronary syndromes and diabetes mellitus. Hellenic J Cardiol. 2016;57(5):375-377.

23. Giraldez RR, Clare RM, Lopes RD, et al. Prevalence and clinical outcomes of undiagnosed diabetes mellitus and prediabetes among patients with high-risk non-ST-segment elevation acute coronary syndrome. Am Heart J. 2013;165(6):918-925.

24. Zand Parsa AF, Ziai H, Haghighi L. The impact of cardiovascular risk factors on the site and extent of coronary artery disease. Cardiovasc $J$ Afr. 2012;23(4):197-199.

25. O’Donoghue ML, Vaidya A, Afsal R, et al. An invasive or conservative strategy in patients with diabetes mellitus and non-ST-segment elevation acute coronary syndromes. J Am Coll Cardiol. 2012;60(2):106-111.

26. Jobs A, Mehta SR, Montalescot G, et al. Optimal timing of an invasive strategy in patients with non-ST-elevation acute coronary syndrome: a meta-analysis of randomised trials. Lancet. 2017;390(10096):737-746.

27. Sheth SD, Giugliano RP. Coronary artery stents: advances in technology Hosp Pract (1995). 2014;42(4):83-91.

28. Iqbal J, Gunn J, Serruys PW. Coronary stents: historical development current status and future directions. Br Med Bull. 2013;106(1):193-11.

29. Alfonso C, Cohen M. Transradial artery catheterization in the United States. Cardiac Interventions Today. 2014:29-34.

30. Katz G, Harchandani B, Shah B. Drug-eluting stents: the past, present and future. Curr Atheroscler Rep. 2015;17(3):485.

31. Pedersen F, Butrymovich V, Kelbæk H, et al. Short-and long-term cause of death in patients treated with primary PCI for STEMI. J Am Coll Cardiol. 2014;64(20):2101-2108.

32. Milojevic M, Thuijs DJ, Head SJ, et al. Life-long clinical outcome afte the first myocardial revascularization procedures: 40-year follow-up after coronary artery bypass grafting and percutaneous coronary intervention in Rotterdam. Interact Cardiovasc Thorac Surg. 2019;28(6):852-859.

33. Alderman E, Andrews K, Bost J, et al. Comparison of coronary bypass surgery with angioplasty in patients with multivessel disease. $N$ Engl J Med. 1996;335(4):217-225.

34. Kapur A, Hall RJ, Malik IS, et al. Randomized comparison of percutaneous coronary intervention with coronary artery bypass grafting in diabetic patients. 1-year results of the CARDia (coronary artery revascularization in diabetes) trial. J Am Coll Cardiol. 2010;55(5):432440.

35. Serruys PW, Ong ATL, van Herwerden LA, et al. Five-year outcomes after coronary stenting versus bypass surgery for the treatment of multivesse disease: the final analysis of the arterial revascularization therapies study (ARTS) randomized trial. $J$ Am Coll Cardiol. 2005;46(4):575-581.

36. Kamalesh M, Sharp TG, Tang XC, et al. Percutaneous coronary intervention versus coronary bypass surgery in United States veterans with diabetes. J Am Coll Cardiol. 2013;61(8):808-816.

37. Bangalore S, Kumar S, Fusaro M, et al. Outcomes with various drug eluting or bare metal stents in patients with diabetes mellitus: mixed treatment comparison analysis of 22, 844 patient years of follow-up from randomised trials. BMJ. 2012;345:e5170.

38. Bangalore LS, Guo LY, Samadashvili LZ, et al. Everolimus eluting stents versus coronary artery bypass graft surgery for patients with diabetes mellitus and multivessel disease. Circ Cardiovasc Interv. 2015;8(7):e002626.

39. Park SJ, Park DW. Diabetes in myocardial revascularization for left main coronary artery disease: predictor or decision maker? J Am Coll Cardiol. 2019;73(13):1629-1632.

40. Holm NR, Mäkikallio T, Lindsay MM, et al. Percutaneous coronary angioplasty versus coronary artery bypass grafting in the treatment of unprotected left main stenosis: updated 5-year outcomes from the randomised, non-inferiority NOBLE trial. Lancet 2020;395(10219):191-199.

41. Stone GW, Sabik JF, Serruys PW, et al. Everolimus-eluting stents or bypass surgery for left main coronary artery disease. $N$ Engl J Med. 2016;375(23):2223-2235.

42. Kappetein AP, Head S. CABG, stents, or hybrid procedures for left main disease? Eurointervention. 2015;11 Suppl V:V111-V114.

43. Herbison P, Wong CK. Has the difference in mortality between percutaneous coronary intervention and coronary artery bypass grafting in people with heart disease and diabetes changed over the years? a systematic review and meta-regression. BMJ Open. 2015;5(12):e010055.

44. Hlatky MA, Boothroyd DB, Bravata DM, et al. Coronary artery bypass surgery compared with percutaneous coronary interventions for multivessel disease: a collaborative analysis of individual patient data from ten randomised trials. Lancet. 2009;373(9670):1190-1197.

45. Aronson D, Edelman ER. Coronary artery disease and diabetes mellitus. Cardiol Clin. 2014;32(3):439-455.

46. Farooq V, Serruys PW, Garcia-Garcia HM, et al. The negative impact of incomplete angiographic revascularization on clinical outcomes and its association with total occlusions. J Am Coll Cardiol. 2013;61(3):282294

47. Ferreiro JL, Angiolillo DJ. Diabetes and antiplatelet therapy in acute coronary syndrome. Circulation. 2011;123(7):798-813.

48. Kaur R, Kaur M, Singh J. Endothelial dysfunction and platelet hyperactivity in type 2 diabetes mellitus: molecular insights and therapeutic strategies. Cardiovasc Diabetol. 2018;17(1):121.

49. Capodanno D, Patel A, Dharmashankar K, et al. Pharmacodynamic effects of different aspirin dosing regiments in type 2 diabetes mellitus patient with coronary artery disease. JACC. 2011;57(14):E1910.

50. Li Z, Denton T, Yeo KK, et al. Off-pump bypass surgery and postoperative stroke: California coronary bypass outcomes reporting program. Ann Thorac Surg. 2010;90(3):753-759.

51. Smart NA, Dieberg G, King N. Long-term outcomes of on-versus off-pump coronary artery bypass grafting. $J$ Am Coll Cardiol. 2018;71(9):983-991.

52. Yamagata KI, Kataoka Y, Kokubu N, et al. A 3-year clinical outcome after percutaneous coronary intervention using sirolimus-eluting stent and off-pump coronary artery bypass grafting for the treatment of diabetic patients with multivessel disease. Circ J. 2010;74(4):671-678. 
53. Sianos G, Morel MA, Kappetein AP, et al. The SYNTAX Score: an angiographic tool grading the complexity of coronary artery disease. EuroIntervention. 2005;1(2):219-227.

54. Tanaka T, Seto S, Yamamoto K, et al. An assessment of risk factors for the complexity of coronary artery disease using the SYNTAX score. Cardiovasc Interv Ther. 2013;28(1):16-21.

55. Head SJ, Milojevic M, Daemen J, et al. Mortality after coronary artery bypass grafting versus percutaneous coronary intervention with stenting for coronary artery disease: a pooled analysis of individual patient data. Lancet. 2018;391(10124):939-948.

56. Wang TKM, Woodhead A, Ramanathan T, et al. Relationship between diabetic variables and outcomes after coronary artery bypass grafting in diabetic patients. Heart Lung Circ. 2017;26(4):371-375.

57. Musa AF, Cheong XP, Yap CG, et al. Does diabetes mellitus increase the mortality risk in coronary artery disease patients undergoing coronary artery bypass grafting surgery at the national heart institute of Kuala Lumpur? J Diabetes Metab Disord Control. 2018;5(4):141-144.

58. Hwang KJ, Lee HS, Song BY, et al. Glycemic Control Status after percutaneous coronary intervention and long-term clinical outcomes in patients with type 2 diabetes mellitus. Circ Cardiovasc Interv. 2017;10(4):e004157.

59. Harskamp RE, Park DW. Percutaneous coronary intervention in diabetic patients: should choice of stents be influenced? Expert Rev Cardiovasc Ther. 2013;11(5):541-553.

60. Corpus RA, George PB, House JA, et al. Optimal glycemic control is associated with a lower rate of target vessel revascularization in treated type II diabetic patients undergoing elective percutaneous coronary intervention. J Am Coll Cardiol. 2004;43(1):8-14.

61. Xu X, Wang R, Wang Y, et al. Glycosylated hemoglobin levels and clinical outcomes in diabetic patients receiving percutaneous coronary interventions: a meta-analysis of cohort studies. Int $J$ Cardiol. 2015;190(1):143-147.

62. Bergmann MJ, Utens EMWJ, de Jager TAJ, et al. Feelings of being disabled as a prognostic factor for mortality in men and women postPCI up to 12years. Int J Cardiol. 2017;249:107-111.

63. Pomero F, Minno M, Fenoglio L, et al. Is diabetes a hypercoagulable state? a critical appraisal. Acta Diabetol. 2015;52(6):1007-1116.

64. Alexopoulos D, Xanthopoulou I, Mavronasiou E, et al. Randomized assessment of ticagrelor versus prasugrel antiplatelet effects in patients with diabetes. Diabetes Care. 2013;36(8):2211-2216.
65. Angiolillo DJ, Badimon JJ, Saucedo JF, et al. A pharmacodynamic comparison of prasugrel vs. high-dose clopidogrel in patients with type 2 diabetes mellitus and coronary artery disease: results of the optimizing anti-platelet therapy in diabetes MellitUS (OPTIMUS)-3 trial. Eur Heart J. 2011;32(7):838-846.

66. Navarese EP, Verdoia M, Schaffer A, et al. Ischaemic and bleeding complications with new, compared to standard, ADP-antagonist regimens in acute coronary syndromes: a meta-analysis of randomized trials. QJM. 2011;104(7):561-569.

67. Song Z, Shen L, Zheng Z, et al. One-stop hybrid coronary revascularization versus off-pump coronary artery bypass in patients with diabetes mellitus. J Thorac Cardiovasc Surg. 2016;151(6):16951701 .

68. Tajstra M, Hrapkowicz T, Hawranek M, et al. Hybrid coronary revascularization in selected patients with multivessel disease: 5-year clinical outcomes of the prospective randomized pilot study. JACC Cardiovasc Interv. 2018;11(9):847-852.

69. Hage A, Giambruno V, Jones P, et al. Hybrid coronary revascularization versus off-pump coronary artery bypass grafting: comparative effectiveness analysis with long-term follow-up. $J$ Am Heart Assoc. 2019;8(24):e014204.

70. Kayatta MO, Halkos ME, Puskas JD. Hybrid coronary revascularization for the treatment of multivessel coronary artery disease. Ann Cardiothorac Surg. 2018;7(4):500-505.

71. Harskamp RE, Brennan JM, Xian Y, et al. Practice patterns and clinical outcomes after hybrid coronary revascularization in the United States: an analysis from the society of thoracic surgeons adult cardiac database. Circulation. 2014;130(11):872-879.

72. Harskamp RE, Walker PF, Alexander JH, et al. Clinical outcomes of hybrid coronary revascularization versus coronary artery bypass surgery in patients with diabetes mellitus. Am Heart J. 2014;168(4):471-478.

73. Saha T, Naqvi SY, Goldberg S. Hybrid revascularization: a review. Cardiology. 2018;140(1):35-44.

74. Repossini A, Tespili M, Saino A, et al. Hybrid coronary revascularization in 100 patients with multivessel coronary disease. The Ann Thorac Surg. 2014;98(2):574-581. 